\title{
REFLECTION
}

\section{What is My Value as a Doctor?}

\author{
Timotby P. Daaleman, DO, MPH
}

Department of Family Medicine, University of North Carolina at Chapel Hill, Chapel Hill, North Carolina
Conflicts of interest: author reports none.

\section{CORRESPONDING AUTHOR}

Timothy P. Daaleman, DO, MPH Department of Family Medicine University of North Carolina at Chapel Hill Campus Box 7595 590 Manning Drive Chapel Hill, North Carolina, 27599-7595 tim_daaleman@med.unc.edu

\begin{abstract}
A weekly habit of viewing my performance data led me to question the value of my doctoring. I tried to answer this quandary in my head for months, but it was a patient encounter that revealed what I had been searching for. As a doctor I am bound to the care of another, especially when disease, disability, or injury create any space between a patient and their personhood. I stand in the breach.

To offset my data habit, I have adopted a practice that reviews my patient care and interior movements at the end of the day. The daily exercise has uncovered a pattern in which my anger, despair, or isolation are invariably are tied to those times when I have failed to stand in the breach with a patient. More importantly, the practice illuminates my finest hours, when I have entered into that chasm with an unstated and binding promise to my patient that they will not be abandoned.
\end{abstract}

Ann Fam Med 2020;18:558-560. https://doi.org/10.1370/afm.2592.

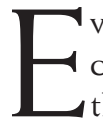
very Monday morning, I have a habit of logging onto our health care system's electronic record to look at my performance data from the prior week. It's a simple task that starts by viewing the tables and graphs of my clinical productivity: a display of the number of patients that I have seen, what I have billed, and how I compare with my colleagues. I then toggle over to stare at a scorecard that reports how my quality of care is measuring up for a panel of patients. The routine ends with a quick glance at a dashboard that lays out my workflow efficiencies in activities such as how long it takes me to complete my notes, or my response time in answering patient messages. After several months my habit became an embedded practice that took only a few minutes, but it surfaced an existential and emotionally charged question about my life's work.

\section{What is My Value as a Doctor?}

Like most physicians I am aware that value has become the holy grail of contemporary medicine, a relentless and elusive quest to achieve patientoriented outcomes in a cost-conscious way. ${ }^{1}$ Although this understanding is grounded in an organizational framework, ${ }^{1}$ I also knew that philosophers had a deeper history of unpacking the concept of value, often distinguishing between intrinsic and extrinsic value. ${ }^{2}$ In simplistic terms, intrinsic value is something that is good in its own right. ${ }^{2}$ Extrinsic value, by contrast, is an entity that is good for the sake of something else to which it is related in some way. ${ }^{2}$

Over time I discovered that my weekly performance review had become a billboard displaying the extrinsic value of my doctoring. On one hand it felt good to see the number of my patients who received preventive services, or my response time in answering their questions. But this positive wave would always quickly crest and break, washing my gladness away in its wake. I started to wonder if these mixed emotions were tied to the realization that many of my functions can now be equivalently provided by others, such as physician assistants and nurse practitioners. ${ }^{3}$ Perhaps I was also awakening to the fact that the competencies 
which differentiate me as a clinician, such as solving a diagnostic conundrum, may someday be vacated by artificial intelligence, which offers the specter of personalizing every diagnosis and treatment decision. ${ }^{4}$

In the ensuing weeks I doubled down to identify a clinical expertise, an interpersonal skill—or any aptitude for that matter - which captured the unique value of my doctoring. I always came up empty. This thought experiment was still on my mind while I was on call in the hospital one weekend and received the following message about my patient who was discharged home after a stroke.

Dr Daaleman, please call wife ASAP. She would like to discuss with you his recent hospital stay, meds, and home health. She feels she is not getting her questions answered. I advised her we were trying to schedule him for a hosp $\mathrm{f} / \mathrm{u}$ appt but she said he is not able to move or get in wheel chair. Please call her ASAP at home. She stated this was very important.

I quickly telephoned and got the story about Abe from Sarah (not their real names). Abe was only 45 years old and had several prior strokes when he was emergently brought to the hospital after being found by the police down in his home. When he was admitted to the neurology service, Abe's head CT revealed a new left ischemic stroke. His hospitalization for nearly 2 weeks included a comprehensive diagnostic evaluation, intensive medical treatment, and multiple rehabilitative therapies. Sarah had called and was panicking since she was not present at Abe's discharge and did not understand his drug regimen. During the call I was able to review the discharge summary and reconcile the medications with Sarah and the local pharmacy, and I asked to see Abe in follow up.

Three days later Abe was wheeled into my clinic by his teenage son. Sarah accompanied them and provided an interim history that the home health agency had established care. My interaction with Abe was difficult, since he had severe language deficits marked by word perseverations, and his physical findings were striking for complete right-sided paralysis. After completing my exam, I studied and signed off on Abe's home health orders, verified his upcoming appointments with the neurologist, and connected Sarah and him with our care manager. As I began to wrap up the encounter and print off the information sheet of his medicines and future appointments, Sarah asked if she could speak with me privately.

"I left Abe about a year ago," were Sarah's first words after Abe and their son left the room. She then told me of the downward spiral of events which fractured their marriage and eventually led to her moving to a town two hours away.
"I was so angry and upset at him that I threw myself into my work after I moved," Sarah continued. "The money was good, and I didn't mind working long hours since I'm good at what I do and it took my mind off of him. I still worried about Abe's health and would call from time to time to check in on him. When he didn't answer for three days straight, I knew something was wrong and called the police."

I stood there and took it all in.

"I knew I had to take care of him when he was in the hospital with the new stroke. I mean we're still husband and wife and I couldn't just put him in a nursing home," Sarah disclosed. "When I went back to our house to get his things, I found bottles of his medicines that were still unopened," she added as tears welled up, "I think he was trying to kill himself after I left."

I could see Sarah processing the series of her misfortunes over the past year. She dried her eyes and gathered herself before turning to me saying in a confessional tone, "I have never told anyone outside of my immediate family what I just told you." Sarah got up and left the room to join her wheelchair-bound husband. And as the door closed behind her, I heard a whispered response to the question that had been haunting me about the value of my life's work.

I stand in the breach.

Standing in the breach goes beyond the foundational clinical skills of demonstrating empathy, engaging in active listening, and being present. As a doctor, it is being bound to the care of another, especially when disease, disability, or injury create any space between a patient and their personhood. I can recall when the disclosure of a terminal diagnosis ripped open my patient's spirit with despair. Throughout the illness course I tried to rethread the seams by affirming his humanity. For another patient the sequelae of a progressive, disabling chronic disease resulted in alienation and overturned the relationships in her family. I struggled many times to be the communication bridge across that canyon. Even when the workflows of my own health care system unknowingly jackhammered the care plans of a homebound patient, I felt responsible for finding the clinical mortar that could patch together a solution.

For many months I had read about and thought hard about the value of doctoring. But it was my encounter with Abe and Sarah that showed me the reality of standing in the breach. I can now see that determining the value of what I do is not important. What is of greater importance is my identity as a physician, and the humdrum work which places me in the midst of the height and depth and width of the human condition. My revelation also helped me to recognize that the weekly performance review blinded me to this 
lived experience. I have tried to stop my data habit but just can't break it. So I told a wise friend about this compulsion and he suggested a daily practice that I have adopted at the end of the day.

The routine begins by settling myself down, looking back at my day in gratitude, and noticing any gifts that I have received. ${ }^{5}$ The gifts may be small and seemingly insignificant, such as the medical assistant who asks how my day is going, or it may be the life event of a patient who receives a report of no evidence of cancer at the five-year mark. The second step involves a review of the day in which I look back and visualize the patients that I have encountered, paying attention to the interior movements and emotions that bubble up. ${ }^{5}$ Why was I so frustrated, for example, that a family refused to consider hospice for their mother who is clearly at the end-of-life? The review can call out those moments when I have fallen short in my doctoring. I close the exercise by acknowledging what has surfaced, and by asking for the grace to move forward the next day. ${ }^{5}$

I am finding that my daily practice is doing more than simply balancing out the weekly performance review. On some days I am seeing a pattern that my anger, despair, or isolation are invariably are tied to those times when I have failed to stand in the breach with a patient. More importantly the exercise illuminates my finest hours, encounters when I have entered into that chasm with an unstated and binding promise to my patient that they will not be abandoned, that they will not face their fears alone. In so doing I offer myself as an invitation to the possibility that healing is always available, a witness to the truth that there is nothing which can separate us from our very selves.

To read or post commentaries in response to this article, see it online at https://www.AnnFamMed.org/content/18/6/558.

Key words: primary care issues; clinician-patient communication/relationship; primary health care; physician-patient relations

Submitted January 7, 2020; submitted, revised, March 26, 2020;

accepted April 13, 2020.

\section{References}

1. Porter ME. What is value in health care? N Engl J Med. 2010; 363(26):2477-2481.

2. Zimmerman MJ, Bradley B. Stanford Encyclopedia of Philosophy. Center for the Study of Language and Information, Stanford University; 2002. Intrinsic vs. Extrinsic Value. Published Oct 22, 2002. Updated Jan 9, 2019. Accessed May 15, 2019. https://plato. stanford.edu/archives/spr2019/entries/value-intrinsic-extrinsic/

3. Morgan PA, Smith VA, Berkowitz TSZ, et al. Impact of physicians, nurse practitioners, and physician assistants on utilization and costs for complex patients. Health Aff (Millwood). 2019;38(6):1028-1036.

4. Rajkomar A, Dean J, Kohane I. Machine learning in medicine. N Engl J Med. 2019;380(14):1347-1358.

5. Thibodeaux M. Reimagining the Ignatian Examen. Chicago, IL: Loyola Press; 2015. 